\title{
Chiral Separation of Catechin by Capillary Electrophoresis with a-Cyclosophorooctadecaose Isolated from Rhodobacter sphaeroides as Chiral Selectors
}

\author{
Chanho Kwon, Daham Jeong, and Seunho Jung* \\ Department of Bioscience and Biotechnology, Bio/Molecular Informatics Center, Konkuk University, Seoul 143-701, Korea \\ *E-mail: shjung@konkuk.ac.kr \\ Received December 31, 2010, Accepted February 7, 2011
}

Key Words : Catechin, Flavanol, $\alpha$-Cyclosophorooctadecaose, Succinate, Anionic additives

\begin{abstract}
$\alpha$-Cyclosophorooctadecaose ( $\alpha-\mathrm{C} 18)$, produced by Rhodobacter sphaeroides, is mainly composed of homogeneous in size, and 18 glucose units per ring as a predominant form. $\alpha$ $\mathrm{C} 18$ is cyclic, and is linked by $\beta-1,2$ linkages and one $\alpha-1,6$ linkage. This backbone is substituted by acetyl ( $0-2$ per mol) and/or succinyl groups (1-7 per mol) as a highly anionic character. ${ }^{1}$ Bacterial genetic analysis is highly developed, as it is a remarkable model for the study of bacterial photosynthesis. $R$. sphaeroides is a facultative photosynthetic member of the alpha-proteobacteria. The strain can heterotrophically grow not only on aerobic respiration but also on anaerobic condition, as it has diverse metabolic pathways. ${ }^{2}$ Although $\alpha-C 18$ of $R$. sphaeroides is believed to play a role in osmotic adaptation, ${ }^{1}$ the exact biological function and roles of $\alpha-\mathrm{C} 18$ remains obscure.
\end{abstract}

Catechin discussed in this work is the major component of tea flavonoids, commonly known as a class of flavan-3-ols. The flavan-3-ols are widespread compounds in the plant kingdom and are found in various natural sources including tea leaves, grape seeds, and the wood and bark of trees such as acacia and mahogany. The flavan-3-ols are reported to possess anti-oxidation, antibiotic, anti-virus, and anti-tumor pharmacological activities and also improve the immune system, reduce blood lipids and steroids, etc. ${ }^{3-8}$ It was reported that $(+)-(2 \mathrm{R} ; 3 \mathrm{~S})$-catechin and $(-)-(2 \mathrm{~S} ; 3 \mathrm{R})$-catechin as chiral drugs showed opposite effects on glycogen metabolism and in membrane fluidity which are responsible for their pharmacological and toxicological mechanisms. ${ }^{9}$ It was also reported that $(-)-(2 S ; 3 R)$-catechin has allelopathic activity, but no antibacterial activity. However, $(+)-(2 \mathrm{R} ; 3 \mathrm{~S})-$ catechin showed antibacterial activity but no allelopathic activity. ${ }^{10}$ Therefore, it is important to consider powerful analytical techniques not only for the evaluation of the total amount of catechin, but also for quantitation of each enantiomer by a rapid and reproducible procedure without tedious and time-consuming pretreatments. The chiral separation of catechin has been performed by high-performance liquid chromatography (HPLC) $)^{11-13}$ and more recently by capillary electrophoresis $(\mathrm{CE})^{14-17}$ with native or modified cyclodextrins as a chiral selector. Recently, a microbial cyclic or noncylic oligosaccharide, produced by sinorhizobial bacteria, was successfully used as a chiral additive for chiral separation of $( \pm)$-catechin in CE. ${ }^{18-21}$

In the present study, we purified $\alpha-\mathrm{C} 18$ from $R$. sphaeroides and used it as a novel chiral additive for chiral catechin in CE. For optimization of the various parameters, $\alpha-C 18$ was investigated as a chiral additive for chiral separation of catechin under various background electrolyte (BGE) conditions such as additive concentration, buffer $\mathrm{pH}$ value, buffer concentration, and temperature. Moreover, through removal of succinyl and acetyl substitutents by alkaline treatment, the role of substitutents was investigated for chiral separation of catechin.

The $\alpha$-cyclosophorooctadecaoses $(\alpha-C 18)$ were extracted from cells of $R$. sphaeroides, which were grown in a LB broth medium by trichloroacetic extraction and purified through chromatographic techniques. ${ }^{1}{ }^{13} \mathrm{C}-\mathrm{NMR}$ spectrum analysis confirmed that the $\alpha-\mathrm{C} 18$ purified from $R$. sphaeroides contains high levels of succinate and acetate (Figs. 2(a) and (b)). In the NMR spectrum, the multiple resonance of $\mathrm{C} 1$ to C5 carbons of $\alpha-\mathrm{C} 18$ was assigned at 105.3, 85.8, 79.1, 76.4 and $72.3 \mathrm{ppm}$, respectively. As the presence of the $\alpha-1,6$

(a)<smiles>Oc1cc(O)c2c(c1)O[C@H](c1ccc(O)c(O)c1)[C@H](O)C2</smiles><smiles>CC(C)[C@H]1c2c(O)cc(O)cc2O[C@H](c2ccc(O)c(O)c2)[C@@H]1O</smiles>

(b)

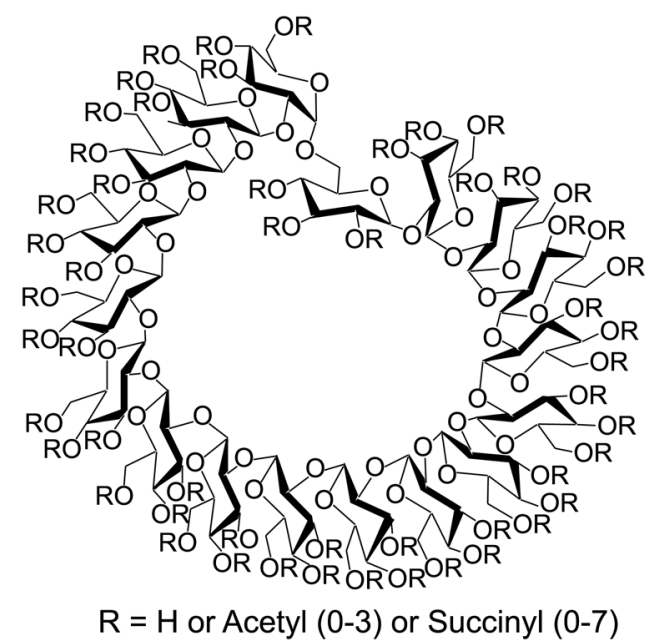

Figure 1. Chemical structures of five flavanones (a), three flavaonone-7- $O$-glycosides and $\alpha$-Cyclosophorooctadecaose $(\alpha$ C18) (b) involved in this work. 
linkage in the $\alpha-\mathrm{C} 18$ produces several distinct chemical shift effects, the resonance of $\mathrm{C} 6(\alpha)(\delta=62 \mathrm{ppm})$ in the $\alpha-1,6$ linkage is shifted upfield relative to the resonances of C6 $(\delta$ $=63-65 \mathrm{ppm})$ in the other $\beta-1,2$ linkages of glucose residues. Each of the C6 resonance linked with succinate and acetate was also shifted significantly downfield to $65.7 \mathrm{ppm}$ and 66.7 ppm, respectively. Moreover, ${ }^{13} \mathrm{C}-\mathrm{NMR}$ spectra by the distortionless enhancement polarization transfer (DEPT) technique showed that $\alpha-\mathrm{C} 18$ contained high levels of succinate and acetate, where signals appeared between 27.3 and 41.4 ppm (methylene carbons $\left(-\mathrm{CH}_{2}-\right)$ of succinate) and between 19.2 and 23.2 ppm (methyl carbons (- $\left.\mathrm{CH}_{3}\right)$ of acetate) (Fig. 2(a)).

The MALDI-TOF mass spectrum of $\alpha-\mathrm{C} 18$ shows the glucans purified from $R$. sphaeroides (Fig 2(c)). Detailed analysis of the spectrum revealed the presence of seven sodiated molecular ions, $[\mathrm{M}+\mathrm{Na}]^{+}$, at $m / z$ 3041.5, 3142.7, $3241.7,3341.7,3441.7,3541.7$, and 3641.7. It was reported that $\alpha-\mathrm{C} 18$ of $R$. sphaeroides has acetyl substitution by one to two acetyl residues. ${ }^{1}$ However, in this study, the obtained molecular signals indicated that $\alpha-\mathrm{C} 18$ has one to even seven succinyl residues and/or one to three acetyl residues as substituents. Based on MALDI-TOF mass spectrometric data, ${ }^{25}$ we calculated the degree of substitution on average and their standard deviations for succinate and acetate as $3.42 \pm 0.72$ and $0.91 \pm 0.31$, respectively. For investigation of the effect of substituents attached to $\alpha-\mathrm{C} 18$, succinates and acetates of highly substituted $\alpha-\mathrm{C} 18$ were removed by alkaline treatment. The exact structure of alkaline treated $\alpha-\mathrm{C} 18$ was also confirmed via a ${ }^{13} \mathrm{C}-\mathrm{NMR}$ spectroscopic analysis and MALDI-TOF mass spectrometry (Figs. 2(b) and (d)). In the DEPT spectral results, succinyl and acetyl groups were completely removed from the $\alpha-\mathrm{C} 18$ backbone where the methylene carbon $\left(-\mathrm{CH}_{2}-\right)$ resonances between 27.3 and $41.4 \mathrm{ppm}$ of succinate and methyl carbon $\left(-\mathrm{CH}_{3}\right)$ resonances between 19.2 and $23.2 \mathrm{ppm}$ of acetate disappeared (Figs. 2(a) and (b)). The MALDI-TOF spectrum also revealed the presence of one molecular ion at $\mathrm{m} / \mathrm{z}$ 2917.7, which indicates the calculated mass for an $[\mathrm{M}+\mathrm{H}]^{+}$ ion of unsubstituted $\alpha-\mathrm{C} 18$ (u $\alpha-\mathrm{C} 18)$. u $\alpha-\mathrm{C} 18$ appears to be mostly homogeneous in size, and it contains only minor amounts of $\alpha-\mathrm{C} 16, \alpha-\mathrm{C} 17$ and $\alpha-\mathrm{C} 19$ (Fig. 2(d)).

We investigated the effective chiral separations of $( \pm)$ catechin under various $\mathrm{CE}$ conditions such as the buffer $\mathrm{pH}$, buffer concentration, temperature, and type and concentration of chiral additives. The effect of type and concentration of $\alpha-\mathrm{C} 18$ was investigated in a fused silica capillary with BGEs in $50 \mathrm{mM}$ borate buffer ( $\mathrm{pH} \mathrm{8.3)} \mathrm{with} \mathrm{various}$ concentrations of chiral additives. Figure 3 shows the partial electropherograms of the chiral separation of $( \pm)$-catechin at $\mathrm{pH}$ 8.3. Without addition of isolated $\alpha-\mathrm{C} 18$, the migration time of $( \pm)$-catechin was $6.72 \mathrm{~min}$, and no separation of $( \pm)$ catechin was achieved. Although the migration time rapidly increased with an increase of $\alpha-\mathrm{C} 18$ concentration, enantiomeric resolution was successfully achieved in BGE containing native $\alpha-\mathrm{C} 18$ at more than $4 \%$ concentration (Fig. 3 ).

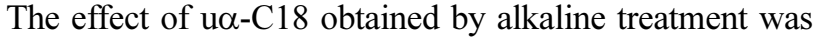
investigated for chiral separation of $( \pm)$-catechin with BGE containing various concentrations of $\mathrm{u} \alpha-\mathrm{C} 18$. As shown in
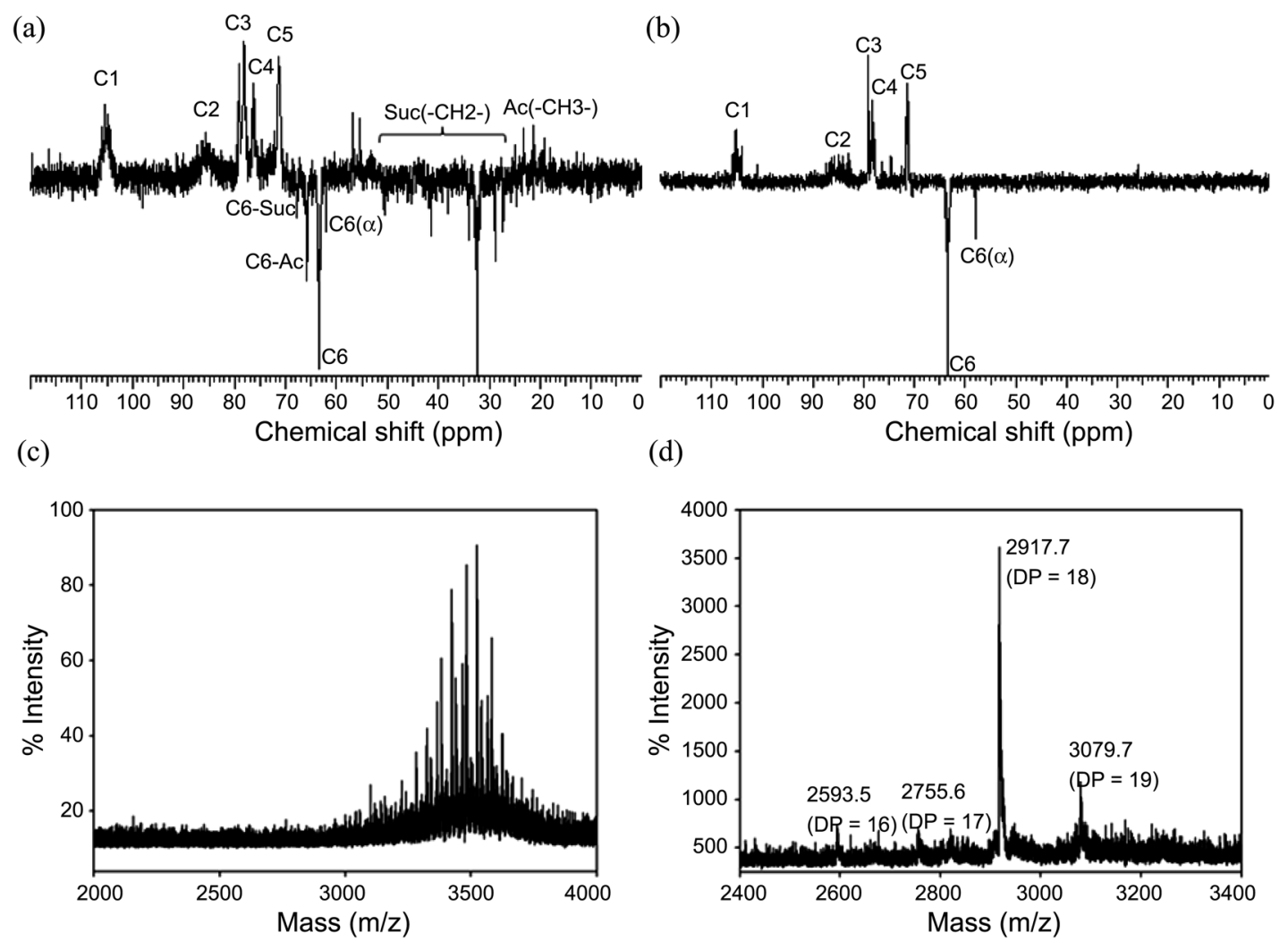

Figure 2. DEPT NMR spectra of the TCA extracted glucans of $R$. sphaeroides (a) and alkaline treated glucans (b). Positive ion MALDITOF mass spectra of the TCA extracted glucans of $R$. sphaeroides $(\mathrm{c})$ and alkaline treated glucans $(\mathrm{d})$. 


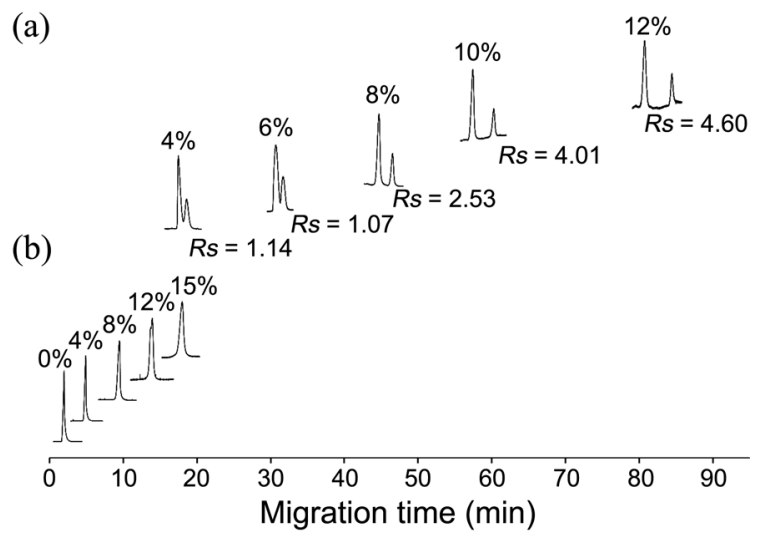

Figure 3. CE separation of $( \pm)$-catechin in $50 \mathrm{mM}$ borate buffer, $\mathrm{pH} 8.3$, containing $\alpha$-cyclosophorooctadecaose $(\alpha-\mathrm{C} 18)(\mathrm{A})$ and no substituted $\alpha$-cyclosophorooctadecaoses (n $\alpha-\mathrm{C} 18)$ by alkaline treatment (B) as chiral additives. Condition: capillary, $50 \mathrm{~cm}(41.5$ $\mathrm{cm}$ effective length $\times 50 \mu \mathrm{m}$ i.d.; applied voltage, $25 \mathrm{kV}$; positive polarity at the inlet, $5 \mathrm{kPa}$ pressure for $4 \mathrm{~s}$; temperature, $20^{\circ} \mathrm{C}$; detection at $220 \pm 10 \mathrm{~nm}$; analyte's composition: $(+) /(-): 2 / 1$.

Figure 3, $\alpha-\mathrm{C} 18$ and u $\alpha-\mathrm{C} 18$ were respectively compared with respect to the chiral separation of $( \pm)$-catechin with various concentrations in the same BGE. In the case of uaC18, no chiral separation occurred in evaluated concentration range, from 4 to $15 \%$ (Fig. 3(b)). However, $\alpha-\mathrm{C} 18$ in BGEs beyond $4 \%$ concentration successfully performed chiral separation of $( \pm)$-catechin. These differences are due to the anionic structure containing the succinate moieties attached to $\alpha-\mathrm{C} 18$, in other words, the succinate moieties were required for effective chiral separation of $( \pm)$-catechin. This suggests that the succinate moieties could be significantly involved in the recognition or discrimination of chiral separation of $( \pm)$-catechin. Although the exact molecular mechanism remains to be determined, the difference of the chiral selection ability of $\alpha-\mathrm{C} 18$ and n $\alpha-\mathrm{C} 18$ could be ascribed to their specific spatial arrangement and their capacity to facilitate hydrogen bondings due to the succinate moieties.

Various buffer solutions including $0.1 \mathrm{M}$ borate $(\mathrm{pH} 8.3$, 8.5, 9.0, and 10.5) and 0.1 $\mathrm{M}$ phosphate $(\mathrm{pH} 7.0,7.5$, and 8.0) buffer were also investigated. The effect of $\mathrm{pH}$ on the chiralseparations and the migration times of $( \pm)$-catechin are depicted in Table 1. At $\mathrm{pH} 7.0$, no chiral separation of catechin was observed even in the presence of $\alpha-\mathrm{C} 18$. This was likely due to the less negative charges of $( \pm)$-catechin at this $\mathrm{pH} .{ }^{22}$ As shown in Table 1 , the chiral resolutions and the migration times of $( \pm)$-catechin increased with increasing $\mathrm{pH}$, and reached a maximum at $\mathrm{pH} 8.3$ and then, slightly decreased at $\mathrm{pH} 8.5$ (Table 1). However, at $\mathrm{pH} 9.0$ and 10.5, the migration times of $( \pm)$-catechin rapidly decreased and no chiral separation occurred even with $\alpha-\mathrm{C} 18$.

To investigate the effect of buffer concentrations, 25 to $100 \mathrm{mM}$ borate buffer with a $25 \mathrm{mM}$ interval was tested for the chiral separation of $( \pm)$-catechin with BGE containing $8 \% \alpha-C 18$. The chiral separations and the migration times of $( \pm)$-catechin on various buffer concentrations are also depicted in Table 1. As shown in Table 1, the chiral resolu-
Table 1. Effect of the buffer $\mathrm{pH}$, concentration of buffer, and temperature on chiral separation of $( \pm)$-catechin

\begin{tabular}{cccccc}
\hline $\begin{array}{c}\text { BGEs } \\
\text { condition }\end{array}$ & & $t_{m 1}(\min )$ & $t_{m 2}(\min )$ & $\begin{array}{c}\text { Selectivity } \\
(\alpha)\end{array}$ & $\begin{array}{c}\text { Resolution } \\
\left(R_{s}\right)\end{array}$ \\
\hline Buffer pH & 7.5 & 39.50 & 42.21 & 1.06 & 2.85 \\
& 8.0 & 54.44 & 58.94 & 1.08 & 2.93 \\
& 8.3 & 56.209 & 61.72 & 1.08 & 4.01 \\
& 8.5 & 52.52 & 55.88 & 1.06 & 0.82 \\
\hline Buffer & 25 & 40.93 & 43.37 & 1.05 & 3.48 \\
Concentration & 50 & 47.22 & 51.27 & 1.08 & 3.83 \\
$(\mathrm{mM})$ & 75 & 49.20 & 51.68 & 1.05 & 3.02 \\
& 100 & 56.20 & 61.72 & 1.09 & 4.01 \\
\hline Temperature & 15 & 52.47 & 57.01 & 1.08 & 3.40 \\
$\left({ }^{\circ} \mathrm{C}\right)$ & 20 & 46.79 & 50.26 & 1.07 & 2.41 \\
& 25 & 38.41 & 40.64 & 1.05 & 2.05 \\
& 30 & 31.256 & 32.703 & 1.04 & 1.71 \\
\hline
\end{tabular}

Condition: capillary, $50 \mathrm{~cm}(41.5 \mathrm{~cm}$ effective length $) \times 50 \mathrm{~m}$ i.d.; applied voltage, $25 \mathrm{kV}$; positive polarity at the inlet, $5 \mathrm{kPa}$ pressure for 4 $\mathrm{s}$; temperature, detection at $220 \pm 10 \mathrm{~nm}$.

tions and the migration times of $( \pm)$-catechin increased with an increase of borate buffer concentrations at $\mathrm{pH} 8.3$, but slightly decreased at $75 \mathrm{mM}$ borate buffer. The advantages of the use of a high ionic strength buffer in CE have been well documented. However, an unlimited increase in the buffer concentration is impossible due to the excessive heat generation in the separation system..$^{23}$ Although the highest resolution of $( \pm)$-catechin is achieved at $100 \mathrm{mM}$ borate buffer, a buffer concentration of $50 \mathrm{mM}$ was chosen for the subsequent optimizing steps.

The effect of temperature was investigated between $15^{\circ} \mathrm{C}$ to $30{ }^{\circ} \mathrm{C}$ at $5{ }^{\circ} \mathrm{C}$ steps for chiral separation of $( \pm)$-catechin with BGEs containing $8 \%$ concentrations of $\alpha-C 18$. The chiral resolution and migration time of $( \pm)$-catechin rapidly decreased as the temperature increased. The migration time $\left(t_{\mathrm{m} 2}\right)$, selectivity $(\alpha)$, and resolution $\left(R_{s}\right)$ obtained at 15 and $30{ }^{\circ} \mathrm{C}$ are $(57.0,1.08,3.40)$ and $(32.7,1.04,1.71)$, respectively. These results show that increase of temperature can enhance the diffusion band broadening and deteriorate the peak efficiency and the resolution. The appropriate temperature was selected through a compromise between lower migration times and higher resolutions. As it provided reasonable run time $\left(t_{m 2}=50.26\right)$ and resolution $\left(R_{s}=2.41\right)$, temperature of $20{ }^{\circ} \mathrm{C}$ was selected.

After optimization of the various parameters, the final conditions were determined as follows for $( \pm)$-catechin: uncoated $50 \mu \mathrm{m}$ ID fused-silica capillary with a total length of 50 (41.5 cm effective length) cm; BGEs, $50 \mathrm{mM}$ borate buffer, pH 8.3; UV detection at $220 \mathrm{~nm}$; anodic injection, 5 $\mathrm{kPa}$ pressure for $4 \mathrm{~s}$; applied voltage, $25 \mathrm{kV}, 20{ }^{\circ} \mathrm{C}$. The electropherogram obtained for $( \pm)$-catechin with $\alpha-C 18$ in the optimal conditions is presented in Figure 3(a).

\section{Experimental Sections}

Chemicals. All chemicals were of analytical grade purity. rac-Catechin and $(+)-(2 \mathrm{R} ; 3 \mathrm{~S})$-catechin were purchased from Sigma Aldrich (St. Louis, Mo, USA). 
Purification of $\boldsymbol{\alpha}$-Cyclosophorooctadecaose. $R$. sphaeroides (ATCC 17023) was grown at $30{ }^{\circ} \mathrm{C}$ in sistrom's succinic acid minimal (SIS) medium under anaerobic condition illuminated with light. ${ }^{1}$ To production of OPGs, aerobic chemoheterotrophic cultures were grown in a Luria-Bertani (LB) broth with shaking. ${ }^{2}$ The bacteria cells were collected after 2 day by centrifugation at $8,000 \mathrm{rpm}$ for 10 minute. The cell pellets were extracted with 5\% trichloroacetic acid, and the extract was neutralized with ammonia water and desalted on a Sephadex G-15 column. The desalted materials was concentrated and applied to a Bio-gel P4 column. The fractions of the putative glucans detected by phenolic sulfuric acid method $^{24}$ were pooled and concentrated by rotary evaporation. Fractions containing oligosaccharides were pooled and lyophilized.

Structural Analyses of $\alpha$-Cyclosophorooctadecaose. For NMR spectroscopic analyses, the glucans were dissolved in $\mathrm{D}_{2} \mathrm{O}$ at room temperature. NMR spectroscopic analysis was performed on a Bruker AMX spectrometer (operated at $500 \mathrm{MHz}$ for ${ }^{1} \mathrm{H}-\mathrm{NMR}, 125 \mathrm{MHz}$ for ${ }^{13} \mathrm{C}-\mathrm{NMR}$ ) at $25{ }^{\circ} \mathrm{C}$. A ${ }^{13} \mathrm{C}-\mathrm{NMR}$ distortionless enhancement polarization transfer (DEPT) spectrum was also obtained at $\theta_{z}=135^{\circ}$ where $-\mathrm{CH}$ and $-\mathrm{CH}_{3}$ signals appeared in the positive phase, with $-\mathrm{CH}_{2}$ in the negative phase. For MALDI-TOF mass spectrometry, the glucans were dissolved in water and mixed with the matrix (2,5-dihydroxybenzoic acid). Mass spectra were recorded on a mass spectrometer (Voyager-DETM STR BioSpectrometry, PerSeptive Biosystems, Framingham, MA, USA) in positive-ion mode.

Deesterification of $\alpha$-Cyclosophorooctadecaose. For removal of the succinyl and acetyl substituents, $\alpha$-cyclosophorooctadecaose were treated in $0.1 \mathrm{M} \mathrm{KOH}$ at $37^{\circ} \mathrm{C}$ for 1 h. After neutralization with AG 50W-X8 (Bio-Rad) on H1 form, the samples were desalted on a Bio-Gel P-2 column. ${ }^{23}$

Capillary Electrophoresis, Instrumentation and Conditions. All capillary electro-phoretic experiments were performed on an Agilent 3-D CE Systems (Wilmington, DE, USA) equipped with a diode array detector. Separations were carried out on uncoated $50 \mu \mathrm{m}$ ID fused-silica capillary with a total length of $50.5 \mathrm{~cm}$ and an effective length of 42 $\mathrm{cm}$ to the detector window. The capillary was conditioned by flushing with $0.1 \mathrm{M} \mathrm{NaOH}$ for $20 \mathrm{~min}$ and then rinsed with water for $10 \mathrm{~min}$, and finally equilibrated with an appropriated running buffer for $3 \mathrm{~min}$. Between two runs, the capillary was rinsed with $0.1 \mathrm{M} \mathrm{NaOH}$, water and running buffer for $3 \mathrm{~min}$ each. The BGEs consisted of an aqueous solution of $100 \mathrm{mM}$ borate buffer ( $\mathrm{pH}$ 8.3). The chiral additive buffer solutions were prepared by dissolved $\alpha$-cyclosophorooctadecaose in the BGEs. The sample solutions were prepared in the running buffer-methanol (9:1) mixture to a final concentration of $0.1 \mathrm{mg} / \mathrm{mL}$ and introduced into the capillary using the pressure of $5 \mathrm{kPa}$ for $4 \mathrm{~s}$. A Voltage of $25 \mathrm{kV}$ was applied with the positive polarity at the inlet. The EOF was determined with methanol as a neutral marker. Detection was done with on-column by multi UV absorbance at 220, 260 and $280 \mathrm{~nm}$.

The peak resolution $(R s)$ and separation selectivity $(\alpha)$ were calculated using the following equations, respectively:

$$
\begin{aligned}
& R s=2\left(t_{m 2}-t_{m 1}\right) /\left(W_{1}+W_{2}\right) \\
& \alpha=t_{m 2} / t_{m 1}
\end{aligned}
$$

Where $t_{m 1}$ and $t_{m 2}$ are the migration times of the first and second enantiomers, $W_{1}$ and $W_{2}$ are the corresponding widths at the peak base.

Acknowledgments. This paper was supported by Konkuk University in 2010. SDG.

\section{References}

1. Talaga, P.; Cogez, V.; Wieruszeski, J.-M.; Stahl, B.; Lemoine, J.; Lippens, G.; Bohin, J.-P. Eur. J. Biochem. 2002, $269,2464$.

2. Zeilstra-Ryalls, J.; Gomelsky, M.; Eraso, J. M.; Yeliseev, A.; O’Gara, J.; Kaplan, S. J. Bacteriol. 1998, 180, 2801.

3. Yáñez, J. A.; Remsberg, C. M.; Miranda, N. D.; Vega-Villa, K. R.; Andrews, P. K.; Davies, N. M. Biopharm. Drug Dispos. 2008, 29, 63.

4. Katiyar, S. K.; Elmets, C. A. Int. J. Oncol. 2001, 18, 1307.

5. Serafini, M.; Bugianesi, R.; Maiani, G.; Valtuena, S.; De Santis, S.; Crozier, A. Nature 2003, 424, 1013.

6. Kazi, A.; Smith, D. M.; Daniel, K.; Zhong, S.; Gupta, P.; Bosley, M.; Dou, Q. P. In Vivo 2002, 16, 397.

7. Yang, C. S.; Maliakal, P.; Meng, X. Annu. Rev. Pharmacol. Toxicol. 2002, 42, 25.

8. Lambert, J. D.; Yang, C. S. Mutat. Res. 2003, 523, 201.

9. Nyfeler, F.; Moser, U. K.; Walter, P. Biochim. Biophys. Acta 1983, $763,50$.

10. Bais, H. P.; Walker, T. S.; Stermitz, F. R.; Hufbauer, R. A.; Vivanco, J. M. Plant Physiol. 2002, 128, 1173.

11. Watanabe, M.; Ayugase, J. J. Agric. Food Chem. 2009, 14, 6438.

12. Rinaldo, D.; Batista, J. M. Jr.; Rodrigues, J.; Benfatti, A. C.; Rodrigues, C. M.; dos Santos, L. C.; Furlan, M.; Vilegas, W. Chirality 2010, 8, 726.

13. Lee, B.-L.; Ong, C.-N. J. Chromatogr. A 2000, 881, 439.

14. Kim, H.; Choi, Y.; Lim, J.; Paik, S.-R.; Jung, S. Chirality 2009, 21, 937.

15. Kofink, M.; Papagiannopoulos, M.; Galensa, R. Molecules 2007, 12,1274 .

16. Kofink, M.; Papagiannopoulos, M.; Galensa, R. Eur. Food Res. Technol. 2007, 225, 569.

17. Kodama, S.; Yamamoto, A.; Matsunaga, A.; Yanai, H. Electrophoresis 2004, 25, 2892.

18. Park, H.; Jung, S. Electrophoresis 2005, 20, 3833.

19. Kwon, C.; Choi, J.; Lee, S.; Park, H.; Jung, S. Bull. Korean Chem. Soc. 2007, 28, 347.

20. Kwon, C.; Yoo, K. M.; Jung, S. Carbohydr. Res. 2009, 344, 1347.

21. Cho, E.; Jung, S. Bull. Korean Chem. Soc. 2009, 30, 2433.

22. Muzolf, M.; Szymusiak, H.; Gliszczyska-Swigo, A.; Rietjens, I. M.; Tyrakowska, B. J. Agric. Food Chem. 2008, 56, 816-823.

23. Chankvetadze, B. Capillary Electrophoresis in Chiral Analysis; Wiley: Chichester, UK, 1997.

24. DuBois, M.; Gilles, K. A.; Hamilton, J. K.; Rebers, P. A.; Smith, F. Anal. Chem. 1956, 28, 350.

25. Jacobs, A.; Lundqvist, J.; Stålbrand, H.; Tjerneld, F.; Dahlman, O. Carbohydr Res. 2002, 337, 711.

26. Kodama, S.; Yamamoto, A.; Matsunaga, A.; Yanai, H. Electrophoresis 2004, 25, 2892.

27. Gotti, R., Furlanetto, S.; Pinzauti, S.; Cavrini, V. J. Chromatogr A 2006, 1112,345 .

28. Gotti, R.; Furlanetto, S.; Lanteri, S.; Olmo, S.; Ragaini, A.; Cavrini, V. Electrophoresis 2009, 30, 2922.

29. Kofink, M.; Papagiannopoulos, M.; Galensa, R. Molecules 2007, 12,1274 .

30. Kofink, M.; Papagiannopoulos, M.; Galensa, R. Eur. Food. Res. Technol. 2007, 225, 569 . 